\title{
UK observatories head for a new management shake-up
}

London. Britain's arrangements for running its ground-based astronomy programmes are being thrown back in the melting pot only three years after the last upheaval, which led to the Royal Greenwich Observatory, now based in Cambridge, and the Royal Observatory in Edinburgh reporting to a single director.

The new moves could lead to the 'privatization' of Britain's telescopes at La Palma, in the Canary Islands, and on Hawaii, both of which are currently financed and run by the Particle Physics and Astronomy Advisory Board (PPARC). They could also result in further changes in the role of the two British 'observatories' - both of which under one scenario might become incorporated into their neighbouring universities.

PPARC officials emphasize that a range of options is currently under consideration for achieving its main objective, namely a separation between bodies responsible for setting policy and funding research, and those responsible for carrying out the resulting research projects.

But they also claim that the various possible changes now being evaluated will address fundamental structural problems that were inadequately resolved in the last shake-up, carried out by its predecessor, the Science and Engineering Research Council.

The new review has been prompted partly by the findings of a committee chaired by Jim Hough of the University of Hertfordshire into arrangements for the support of optical infrared millimetre astronomy, whose findings were presented to the full council last Thursday (16 February).

The panel gave a general endorsement of the high quality of research currently being funded by PPARC in optical astronomy. It also supporteed maintaining a 'suite' of ground-based telescopes to complement the new international twin 8-metre Gemini telescopes, currently under construction in Hawaii and Chile.

Both conclusions have been welcomed by PPARC. But there has been less consensus on changes proposed by the panel to increase the effectiveness with which research at the telescopes is organized.

The Hough review itself suggests that both the sites in La Palma and Hawaii should be allowed to operate as autonomous bodies. These would be managed by another organization - suggestions range from an individual university to the newlyautonomous Daresbury and Rutherford Appleton Laboratory - and subsequently apply to PPARC for funding.

The review panel also recommends that the task of preserving Britain's national capability in telescope instrumentation should be made the responsibility of a "UK astronomy centre".

In responding to the panel's conclusions, the full council said it endorsed the idea inherent in encouraging the telescope sites to operate autonomously by ensuring that accountability and responsibility "should be devolved as far down the operational chain as possible."

It also accepted the need to maintain UK excellence in telescope instrumentation development. But council officials are cautious over the specific proposal for a national centre made by the Hough panel, suggesting that the costs and benefits of such a plan need to be carefully compared to those of other options - which might be transferring such responsibility to an existing

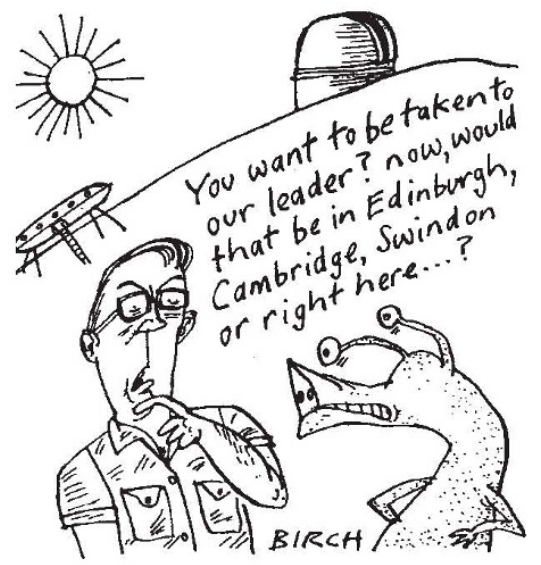

body, or leaving universities to carry out the work on a decentralized basis.

Indeed, the council itself is said to have been split over the major thrust of the changes, some members arguing that, since the present arrangements appear to be working successfully, there does not seem to be a pressing need for change.

In concrete terms, one focus of the debate is whether, if the telescopes are to be 'privatized', then each should apply separately to PPARC for funding - or whether their research strategies should be co-ordinated by a new committee.

Given the many uncertainties that exist, PPARC's decision to make a careful costbenefit analysis of its options has been widely welcomed. Alec Boksenberg, for example, the director of the Royal Observatories, says he is "pleased that there will be some real in-depth studies of the different options before any decisions are taken."

PPARC itself accepts that many of the costs of a major restructuring - such as those involved in handing over responsibility to a university - need careful assessment. But it hopes to have sufficient calculations completed by its next meeting in May to reduce the "delay and uncertainty" caused by the current debate.

David Dickson

\section{Institute Pasteur to adopt 'automatic' misconduct process}

Paris. The Institut Pasteur in Paris has established a new set of administrative procedures which it says it intends to apply "automatically" to all suspected cases of scientific misconduct.

According to internal Pasteur documents, the move has been prompted partly by controversy last year over the handling of a previous relatively minor case of scientific misconduct at the institute (see Nature 369, $266 ; 1994)$. But the documents also give as a broader reason the "evolution of the general context of research".

Under the new system, allegations of "lack of scientific integrity" will, in the first instance, be assessed by the management of the Institut Pasteur. If it is decided to take the issue further, an investigatory commission will be appointed, made up of three to five members of the institute's scientific board and supplemented by outside scientists if particular expertise is required.

Misconduct is defined as "deliberate fabrication of experiments, presentation of falsified results" or "the theft of other people's data". The commission would interview those accused, as well as other witnesses. If it confirmed that grounds existed to suspect misconduct, then the institute's standard disciplinary procedures would be invoked.

Labour union representatives of staff at the institute have generally welcomed the move, in particular because it adds a preliminary step before the existing disciplinary procedures, which they consider ill-suited, if followed in isolation, for misconduct cases.

In particular, it has been argued that the formal nature of current procedures carries a double jeopardy; management is often reluctant to use them, while those subjected to the procedures risk damage to their reputation, even if subsequently exonerated.

But staff representatives are also critical of the fact that, under the new system, the investigatory commission will be nominated by the Pasteur management. They claim that this opens the possibility of individuals being accused of misconduct (or protected against such charges) on political grounds, and that an independent, elected commission would have been preferable, in that it would provide "absolute transparency".

Maxime Schwartz, the director general of the institute, points out however that onethird of the institute's scientific board, from which the commissions would be drawn, are elected by Pasteur staff, while a further third are scientists from outside the institute.

Other observers say the move reflects a shift at Pasteur away from considering all cases of misconduct as major crimes, leading inevitably to the end of a researcher's career - and also harming the institute's reputation if publicized.

Declan Butler 